\title{
AN ENHANCED CLUSTERING APPROACH FOR ENERGY EFFICIENT ROUTING IN WIRELESS SENSOR NETWORKS
}

\author{
Harpinderjeet Kaur Sekhon (1), Dr. Mohita (2) \\ (1) Research Scholar, Department of Computer Science and Engineering, NWIET, Moga \\ (2) Associate Professor, Department of Computer Science and Engineering, NWIET, Moga
}

\begin{abstract}
Energy consumption is the core issue in wireless sensor networks (WSN). To generate a node energy model that can accurately reveal the energy consumption of sensor nodes is an extremely important part of protocol development, system design and performance evaluation in WSNs. In this paper, by studying component energy consumption in different node states and within state transitions, the authors present the energy models of the node core components, including processors, RF modules and sensors. One of the major issues in wireless sensor networks is developing a routing protocol which has a significant impact on the overall lifetime of the sensor network. The network area is divided into same sized small-small regions. Sensor nodes are randomly deployed in each predefined sub-area. Each region will have its region head $(\mathrm{RH})$ and multiple member nodes. The member nodes in a specific region will send the data to the $\mathrm{RH}$. $\mathrm{RH}$ within the region will be elected by distributed mechanism and will be based on fuzzy variables. It was found that the proposed algorithm gives a much improved network lifetime as compared to existing work. Based on our model, transmission tuning algorithm for cluster-based WSNs has been proposed to balance the load among cluster heads that fall in different regions. This algorithm is applied prior to a cluster algorithm to improve the performance of the clustering algorithm without affecting the performance of individual sensor nodes.
\end{abstract}

\section{KEYWORDS}

Wireless, Sensor Networks, Protocol, Cluster Head, WSN, Fuzzy Logic.

\section{INTRODUCTION}

Wireless Sensor Network (WSN) is a class of wireless adhoc networks which consists of spatially distributed autonomous sensor nodes to monitor physical or environmental conditions, such as temperature, sound, pressure, etc at different locations. Energy consumption is the core issue in wireless sensor networks because nodes are battery operated. It is desirable to make these nodes as cheap and energy-efficient as possible and rely on their large numbers to obtain high quality results. Consequently many protocols have been proposed in order to minimize the energy consumption of these nodes. Wireless Sensor Network (WSN) is a type of wireless Ad-Hoc network in which large numbers of sensor nodes are deployed in the application field [1]. Sensor nodes are inexpensive and low power devices. Each node consists of four main units: Sensing Unit, Processing Unit, Communicating Unit and Power Unit. In sensing unit one or more sensors are placed to sense different environment parameters like sound, temperature, vibration, pressure, motion and etc., based on application requirement. Sensed data's (analog or digital) are processed and aggregated in the processing unit.

The need for energy-efficient infrastructures for sensor networks is becoming increasingly important. Wireless sensor networks are networks consisting of many sensor nodes that communicate over a wireless media. A sensor node is equipped with a sensor module, a processor, a radio module and a battery. Since the battery limits the lifetime of the sensor nodes it also limits the lifetime of the sensor network, thus energy efficiency is a major issue for sensor networks.

An important goal in many sensor networks is to monitor an area as long time as possible. Hence, it is important to distribute energy consumption evenly across the network. When the energy consumption is evenly distributed, the major part of the sensor nodes will stay alive approximately equally long time. This enables continued information gathering throughout the whole network area during the lifetime of the network. The most power-consuming activity of a sensor node is typically radio communication [10]. Hence, radio communication must be kept to an absolute minimum. This means that the amount of network traffic should be minimized. In order to reduce the amount of traffic in the network, we build clusters of sensor nodes as proposed in e.g. $[1,3,9]$. Some sensor nodes become cluster heads and collect all traffic from their respective cluster. The cluster head aggregates the collected data and then sends it to its base station. When using clustering, the workload on the cluster head is thus larger than for non-cluster heads. The cluster heads should therefore be changed several times during the lifetime of the sensor network in order to distribute the extra workload and energy consumption evenly. Sensor nodes are deployed for pervasive computing. Each of the sensor node is capable of limited amount of processing, upon coordination with the other node's information, gains the power to accomplish complex functionalities. Thus in Wireless Sensor Network (WSN), a collection of the sensor coordinates well with each other, using wireless communication link, in order to pursue some specific tasks.

\section{LITERATURE SURVEY}

LEACH (Low-Energy Adaptive Clustering Hierarchy) [3] is a TDMA cluster based approach where a node elects itself to be cluster head by some probability and broadcasts an advertisement message to all the other nodes in the network. A non cluster head node selects a cluster head to join based on the received signal strength. Being cluster head is more energy consuming than to be a non cluster head node, since the cluster head needs to receive data from all cluster members in its cluster and then send the data to the base station. All nodes in the network have the potential to be cluster head during some periods of time. The TDMA scheme starts every round with a set-up phase to organize the clusters. After the set-up phase, the system is in a steady-state phase for a certain amount of time. The steady-state phases 
consist of several cycles where all nodes have their transmission slots periodically. The nodes send their data to the cluster head that aggregates the data and send it to its base station at the end of each cycle. After a certain amount of time, the TDMA round ends and the network re-enters the set-up phase.

LEACH-C (LEACH-Centralized) [2] is a variant of LEACH that uses a centralized cluster formation algorithm to form clusters. The protocol uses the same steady-state protocol as LEACH. During the set-up phase, the base station receives information from each node about their current location and energy level. After that, the base station runs the centralized cluster formation algorithm to determine cluster heads and clusters for that round. LEACH-C uses simulated annealing [4] to search for near-optimal clusters. LEACH-C chooses cluster heads randomly but the base station makes sure that only nodes with "enough" energy are participating in the cluster head selection. Once the clusters are created, the base station broadcasts the information to all the nodes in the network. Each of the nodes, except the cluster head, determines its local TDMA slot, used for data transmission, before it goes to sleep until it is time to transmit data to its cluster head, i.e., until the arrival of the next slot.

A further development is LEACH-F (LEACH with Fixed clusters) [2]. LEACH-F is based on clusters that are formed once and then fixed. Then, the cluster head position rotates among the nodes within the cluster. The advantage with this is that, once the clusters are formed, there is no set-up overhead at the beginning of each round. To decide clusters, LEACH-F uses the same centralized cluster formation algorithm as LEACH-C. The fixed clusters in LEACH-F do not allow new nodes to be added to the system and do not adjust their behavior based on nodes dying.

In [4], Two-level LEACH (TL-LEACH) is proposed to solve the above mentioned issue. A CH collects the data from nodes and forwards the aggregated data to another $\mathrm{CH}$, which is placed between base and first $\mathrm{CH}$. It reduces transmission cost and another $\mathrm{CH}$ act as a relay node. Paper [5], proposed alternate solution called Multi-hop LEACH, which converts onehop communication to multi-hop communication. But it adds two overloads to the network: first one is the additional routing overload and second is the relay nodes nearby base station that gets overloaded and chance to drain quickly.

V-LEACH in [6] introduces vice-cluster heads, i.e., alternate $\mathrm{CH}$. IT consists of a Ch node, Vice $-\mathrm{CH}$ node and member nodes. If $\mathrm{CH}$ fails due to low energy, then vice- $\mathrm{CH}$ takes charge and continues the transmission without braking the network. But it overloads an additional node (vice- $\mathrm{CH}$ ) other than $\mathrm{CH}$ to main all information including members list and data. This will reduce the life time of the node. In large scale network, paper [2] identifies the hidden area, which far away from base and has high Minimum Reachable Power (MRP). The identified zone is called Far-Zone and it's separated from main cluster, after formation of the current round of cluster. It selects Zone head, which is responsible to collect and forward information from that zone to nearby cluster head. It avoids breakdown of specific area (hidden zone) from the network.

Due to the deployment of WSNs in unattended harsh environment conditions, it gets to be unrealistic to charge or replace their batteries. Accordingly, the energy efficient operation of wireless sensors is very important to prolong the lifetime of overall wireless sensor networks. Furthermore, in WSN, there is wireless communication among all the nodes. Moreover, the energy consumed to transmit a message is exceptionally more than the energy needed to receive the same message. Besides all this, the route of each message destined to the base station too decides the network lifetime; for example, any node with depleted battery in short routes to the base station may lead to decreased network lifetime. While, using a long route composed of many sensor nodes can significantly increase the network delay.

\section{CLUSTERING PARAMETERS}

- Number of clusters (cluster count): In most recent probabilistic and randomized clustering algorithms the $\mathrm{CH}$ election and formation process lead naturally to variable number of clusters. In some published approaches, however, the set of $\mathrm{CHs}$ are predetermined and thus the number of clusters are preset. The number of clusters is usually a critical parameter with regard to the efficiency of the total routing protocol.

- Intracluster communication: In some initial clustering approaches the communication between a sensor and its designated $\mathrm{CH}$ is assumed to be direct (one-hop communication). However, multi-hop intracluster communication is often (nowadays) required, i.e., when the communication range of the sensor nodes is limited or the number of sensor nodes is very large and the number of $\mathrm{CHs}$ is bounded.

- Nodes and CH mobility: If we assume stationary sensor nodes and stationary $\mathrm{CHs}$ we are normally led to stable clusters with facilitated intracluster and intercluster network management. On the contrary, if the $\mathrm{CHs}$ or the nodes themselves are assumed to be mobile, the cluster membership for each node should dynamically change, forcing clusters to evolve over time and probably need to be continuously maintained.

- Nodes types and roles: In some proposed network models (i.e., heterogeneous environments) the CHs are assumed to be equipped with significantly more computation and communication resources than others. In most usual network models (i.e., homogeneous environments) all nodes have the same capabilities and just a subset of the deployed sensors are designated as $\mathrm{CHs}$.

- Cluster formation methodology: In most recent approaches, when $\mathrm{CHs}$ are just regular sensors nodes and time efficiency is a primary design criterion, clustering is being performed in a distributed manner without coordination. In few earlier approaches a centralized (or hybrid) approach is followed; one or more coordinator nodes are used to partition the whole network off-line and control the cluster membership. 
- Cluster-head selection: The leader nodes of the clusters (CHs) in some proposed algorithms (mainly for heterogeneous environments) can be pre-assigned. In most cases however (i.e., in homogeneous environments), the $\mathrm{CHs}$ are picked from the deployed set of nodes either in a probabilistic or completely random way or based on other more specific criteria (residual energy, connectivity etc.).

\section{PROPOSED METHODOLOGY}

- $\quad$ All the nodes in the WSN network are homogeneous and base station is located outside the network area. The network area is divided into grid of multiple regions of equal size. Different amplification energies have been used over here.

- The base station is mobile and the nodes are randomly scattered in the field.

- The clusters in the network are created with the help of centralized approach.

- Base station will send its location to all the sensor nodes by advertising the "HELLO" message

- The sensor nodes will receive the message from the base station and will send the acknowledgement with their location coordinates, remaining energy and number of neighbors to the base station.

- On receiving the messages, the base station will form the clusters and will advertise the Cluster Head and Member nodes of that cluster to all the nodes.

- The base station will use the fuzzy logic rule for the selection of cluster head.

- The distance to base station, number of neighbors and residual energy acts as an input parameters to the fuzzy interference system.

- The Base Station will categorize the cluster heads into 2 groups: Boundary $\mathrm{CH}$ and Non-Boundary $\mathrm{CH}$.

- The boundary cluster heads are closer to the base station and therefore only boundary cluster heads will send the data to the base station.

- Node goes into sleeping state if its remaining energy is less than $10 \%$ of the original allocated energy and will only send the packets after a definite interval. It will not send the packets in all the rounds.

- The non-boundary cluster head will chose the cluster head in the next relay node according to the minimum distance from its current location to the base station.

- The boundary cluster head will collect the data from its own region and from the cluster head of another regions and will send the data to the base station only when it is available in its region.

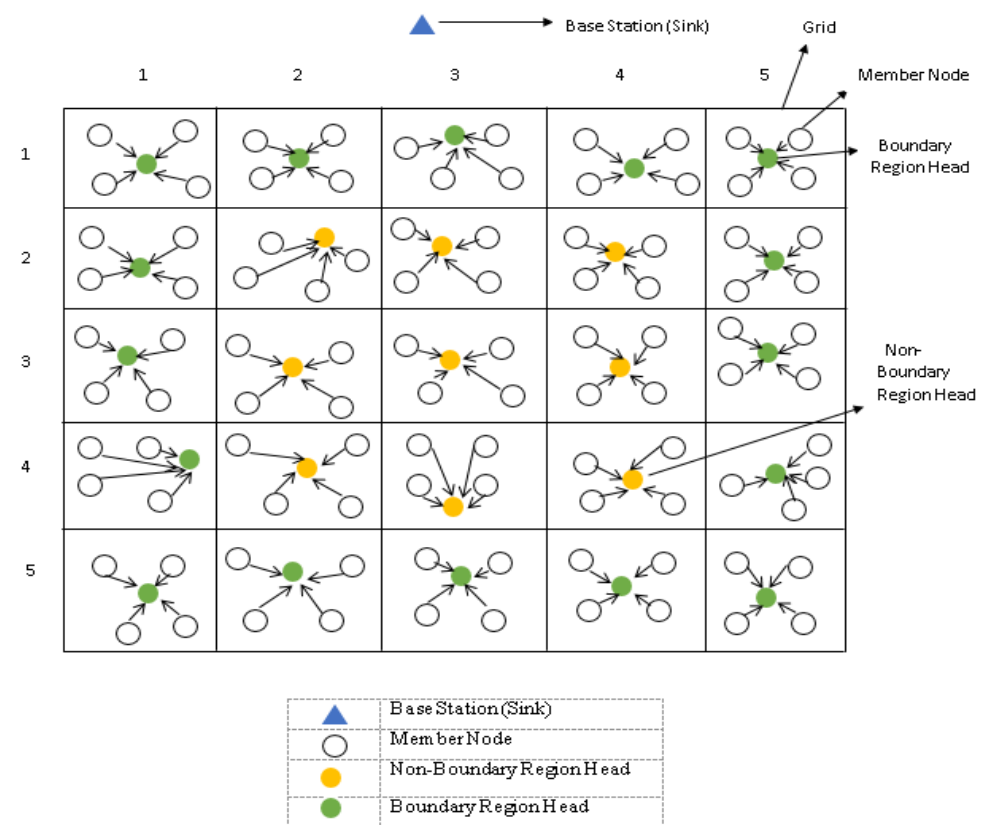

Figure 1. Region Based Clustering

The following figure 1 represents the region based clustering. The whole network is divided into small-small regions. The sensor nodes are randomly deployed in these sub-areas. Each region has its region head. The regions along the boundary have boundary region head and the regions that are not along the boundary have the non-boundary region heads. The member nodes send their data to the region heads. 


\section{FUZZY RULE BASE SYSTEM}

Multiple parameters have been used for the election of region head. The Distance to base station, number of neighbors and residual energy are evaluated for each and every node in the region for the election mechanism. The decision of selection of region head is based on different scenarios. All the possible cases are listed in the table 1.

Table 1. Fuzzy Rule Base System

\begin{tabular}{|c|c|c|c|c|}
\hline S. NO. & $\begin{array}{l}\text { RESIDUAL } \\
\text { ENERGY }\end{array}$ & $\begin{array}{l}\text { DISTANCE OF } \\
\text { BASE STATION }\end{array}$ & $\begin{array}{l}\text { NUMBER OF } \\
\text { NEIGHBORS }\end{array}$ & CHANCE TO SELECT REGION HEAD \\
\hline 1 & LOW & CLOSE & LOW & MEDIUM LOW \\
\hline 2 & LOW & CLOSE & MEDIUM & VERY HIGH MEDIUM \\
\hline 3 & LOW & CLOSE & $\mathrm{HIGH}$ & VERY LOW HIGH \\
\hline 4 & LOW & MEDIUM & LOW & LOW MEDIUM \\
\hline 5 & LOW & MEDIUM & MEDIUM & MEDIUM \\
\hline 6 & LOW & MEDIUM & $\mathrm{HIGH}$ & MODERATELY LOW HIGH \\
\hline 7 & LOW & FAR & LOW & VERY VERY LOW \\
\hline 8 & LOW & FAR & MEDIUM & VERY LOW \\
\hline 9 & LOW & FAR & $\mathrm{HIGH}$ & RELATIVELY MEDIUM LOW \\
\hline 10 & MEDIUM & CLOSE & LOW & VERY LOW MEDIUM \\
\hline 11 & MEDIUM & CLOSE & MEDIUM & MODERATELY LOW MEDIUM \\
\hline 12 & MEDIUM & CLOSE & $\mathrm{HIGH}$ & RELATIVELY LOW HIGH \\
\hline 13 & MEDIUM & MEDIUM & LOW & RELATIVELY LOW MEDIUM \\
\hline 14 & MEDIUM & MEDIUM & MEDIUM & RATHER MEDIUM \\
\hline 15 & MEDIUM & MEDIUM & $\mathrm{HIGH}$ & RELATIVELY HIGH MEDIUM \\
\hline 16 & MEDIUM & FAR & LOW & RATHER LOW \\
\hline 17 & MEDIUM & FAR & MEDIUM & HIGH LOW \\
\hline 18 & MEDIUM & FAR & $\mathrm{HIGH}$ & VERY HIGH LOW \\
\hline 19 & $\mathrm{HIGH}$ & CLOSE & LOW & LOW HIGH \\
\hline 20 & $\mathrm{HIGH}$ & CLOSE & MEDIUM & HIGH MEDIUM \\
\hline 21 & $\mathrm{HIGH}$ & CLOSE & $\mathrm{HIGH}$ & VERY VERY HIGH \\
\hline 22 & $\mathrm{HIGH}$ & MEDIUM & LOW & RATHER HIGH \\
\hline 23 & $\mathrm{HIGH}$ & MEDIUM & MEDIUM & $\mathrm{HIGH}$ \\
\hline 24 & $\mathrm{HIGH}$ & MEDIUM & $\mathrm{HIGH}$ & VERY HIGH \\
\hline 25 & $\mathrm{HIGH}$ & FAR & LOW & LOW \\
\hline 26 & $\mathrm{HIGH}$ & FAR & MEDIUM & RELATIVELY HIGH LOW \\
\hline 27 & $\mathrm{HIGH}$ & FAR & $\mathrm{HIGH}$ & MEDIUM HIGH \\
\hline
\end{tabular}




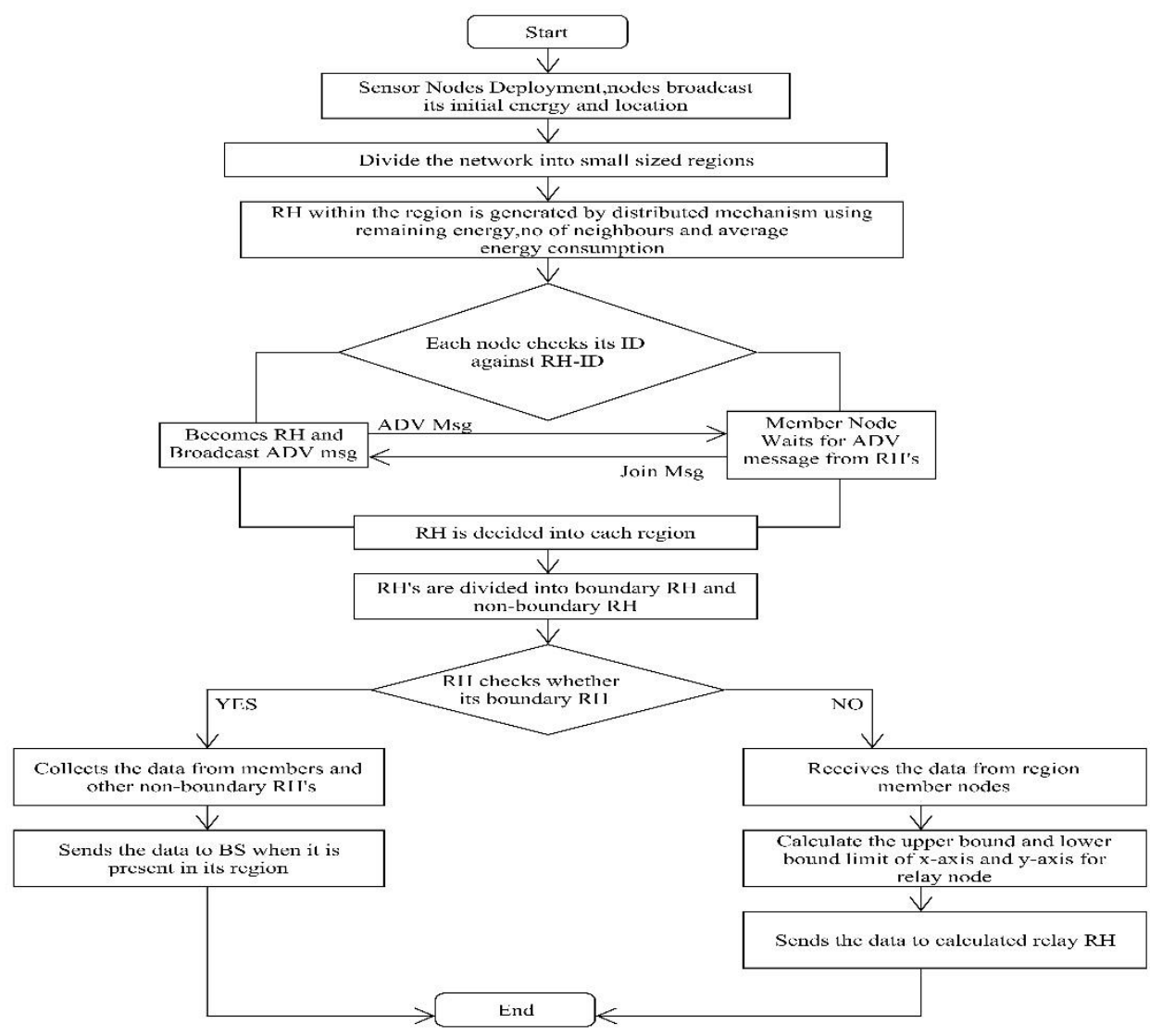

Figure 2. Flow of work

\section{RESULTS AND DISCUSSION}

This section presents the simulation results of the work done and the proposed approach. The proposed approach has been implemented in MATLAB. The parameters required for the simulation is shown in the following Table 2.

Table 2. Simulation Parameters

\begin{tabular}{|c|c|}
\hline Network Parameters & Values \\
\hline Network Size & $100 \mathrm{~m}^{\star} 100 \mathrm{~m}$ \\
\hline Number of Sensor Nodes & 200 \\
\hline Initial Energy of Sensor Nodes & $0.5 \mathrm{~J}$ \\
\hline Packet Size & $4000 \mathrm{bits}$ \\
\hline Data Aggregation Energy consumption & $5 \mathrm{~nJ} / \mathrm{bit}$ \\
\hline Amplification Energy (Cluster to BS) $\mathrm{d}>=\mathrm{d} 0$ & $\mathrm{Efs}=10 \mathrm{pJ} / \mathrm{bit} / \mathrm{m} 2$ \\
\hline Amplification Energy (Cluster to BS) $\mathrm{d}<=\mathrm{do}$ & $\mathrm{Emp}=0.0013 \mathrm{pJ} / \mathrm{bit} / \mathrm{m} 2$ \\
\hline
\end{tabular}

The network area is of $100^{\star} 100 \mathrm{~m}$. The network area is divided into small regions of $20^{\star} 20 \mathrm{~m}$ each. Each region has its own cluster head. The base station is movable. It will move along the boundary of the network. The region heads are divided into two classes namely Boundary Region head and Non-Boundary region heads. Boundary RH will send the data to the $\mathrm{BS}$ only when it will come within its region. When boundary $\mathrm{RH}$ is sending its data to the BS, the other nodes will not send the data to that specific boundary $\mathrm{RH}$ and Non-boundary region heads will evaluate the lower bound limit and upper bound limit of both $x$-axis and $y$-axis to evaluate the next relay node. It will choose the relay node on the path where BS is closely located. The following figure represents the network where all the nodes are alive. The figure also represents the sink node as well as source nodes. 


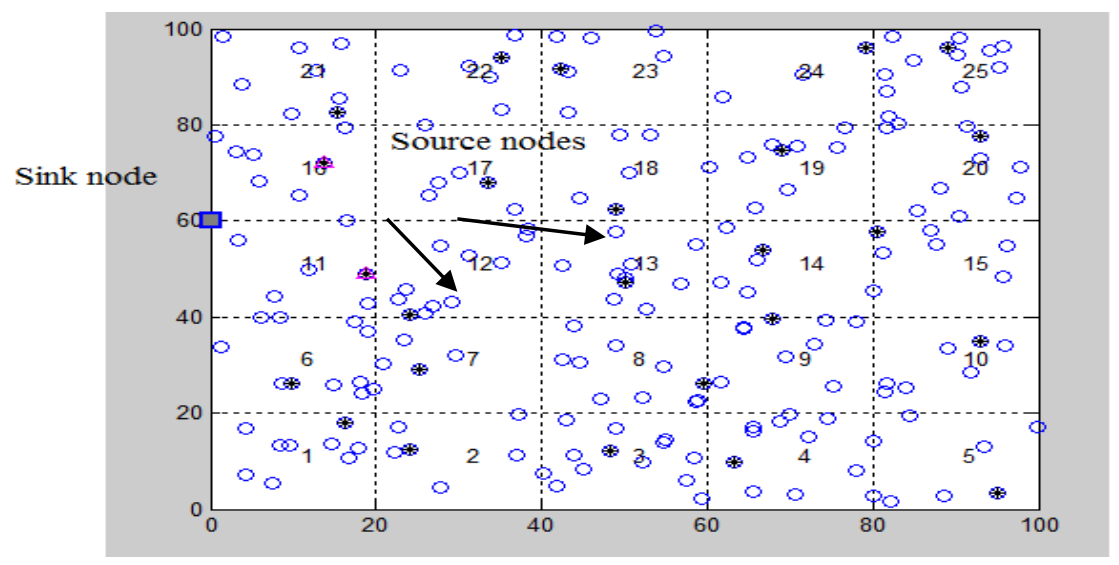

Figure 3. Network when nodes are Alive

The following figure represents the network where some of the nodes are dead. With the passage of the time the energy of the nodes decreases. So the nodes become dead.

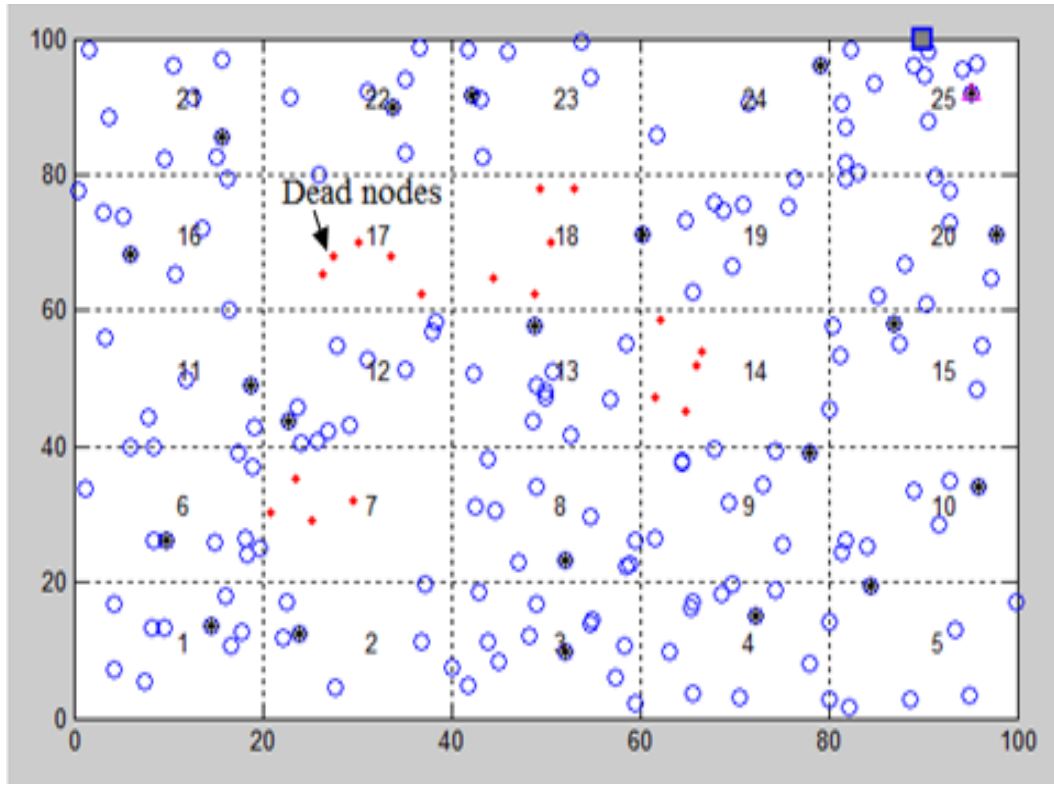

Figure 4. Network when some nodes are Dead

\section{NETWORK LIFE TIME}

The lifetime of network depends upon the number of Dead \& Alive Nodes. The proposed scheme plays an important role to achieve better network life time. Figure 5 clearly represents the longer stability of the proposed scheme. An equal energy is consumed by each node in each round and some nodes get dead with variation of time. The proposed scheme achieves more stability period and longer network lifetime.

Table 3. Comparison of existing and current work with energy $=0.50 \mathrm{~J}$

\begin{tabular}{|c|c|c|c|c|c|c|}
\hline $\begin{array}{c}\text { ENERGY } \\
=.50 J\end{array}$ & \multicolumn{3}{|c|}{ EXISTING WORK } & \multicolumn{3}{c|}{ CURRENT WORK } \\
\hline S.No. & FND & MND & LND & FND & MND & LND \\
\hline 1 & 621 & 155 & 1236 & 1405 & 2392 & 2483 \\
\hline 2 & 605 & 154 & 1239 & 1422 & 2388 & 2470 \\
\hline 3 & 621 & 1155 & 1236 & 1422 & 2388 & 2470 \\
\hline 4 & 606 & 1159 & 1244 & 1422 & 2388 & 2470 \\
\hline 5 & 607 & 1146 & 1227 & 1708 & 2359 & 2484 \\
\hline
\end{tabular}




\begin{tabular}{|c|c|c|c|c|c|c|}
\hline 6 & 615 & 1149 & 1241 & 1420 & 2402 & 2468 \\
\hline 7 & 607 & 1155 & 1238 & 1420 & 2402 & 2468 \\
\hline 8 & 606 & 1159 & 1244 & 1422 & 2388 & 2470 \\
\hline 9 & 615 & 1149 & 1241 & 1708 & 2359 & 2484 \\
\hline 10 & 607 & 1155 & 1238 & 1422 & 2388 & 2470 \\
\hline
\end{tabular}

Table 4. Comparison of existing and current work with energy $=0.25 \mathrm{~J}$

\begin{tabular}{|c|c|c|c|c|c|c|}
\hline \multirow{2}{*}{ ENERGY =.25J } & \multicolumn{5}{|c|}{ EXISTING WORK } & \multicolumn{3}{c|}{ CURRENT WORK } \\
\hline S. No. & FND & MND & LND & FND & MND & LND \\
\hline 1 & 300 & 578 & 621 & 627 & 1201 & 1237 \\
\hline 2 & 289 & 579 & 616 & 630 & 1195 & 1235 \\
\hline 3 & 304 & 575 & 621 & 797 & 1189 & 1248 \\
\hline 4 & 304 & 578 & 621 & 627 & 1201 & 1237 \\
\hline 5 & 309 & 578 & 619 & 627 & 1201 & 1237 \\
\hline 6 & 304 & 579 & 623 & 630 & 1195 & 1235 \\
\hline 7 & 308 & 576 & 620 & 797 & 1189 & 1248 \\
\hline 8 & 304 & 578 & 621 & 653 & 1186 & 1247 \\
\hline 9 & 294 & 576 & 619 & 642 & 1189 & 1248 \\
\hline
\end{tabular}

From the above Table 4 and 3, where various experiments has been done shows that the proposed work is more better than the existing work. It also shows that proposed model has high network lifetime efficiency as compared to the existing model.
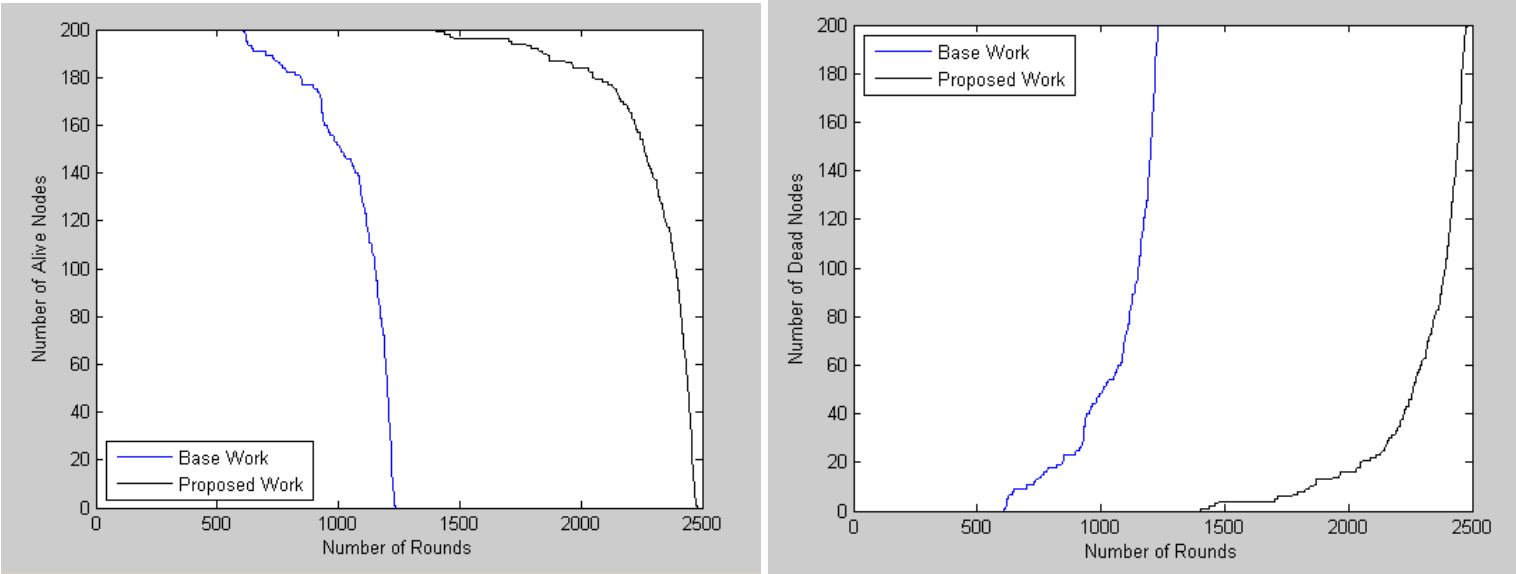

Figure 5. Analysis of Alive nodes and Dead Nodes

We can see that almost all the sensors are alive for the proposed algorithm for quite long period of time, hence extending the network efficiency. For existing algorithm, as no. of dead sensors will increase, their efficiency will decrease.

\section{ENERGY CONSERVATION}

Figure 6 represents the average energy consumed by the network during each round of the transmission time. The average energy consumed by the proposed algorithm is minimum as compared to the existing algorithm. In wireless networking, average remaining energy means the remaining lifetime of a wireless link on arrival of a new packet. 

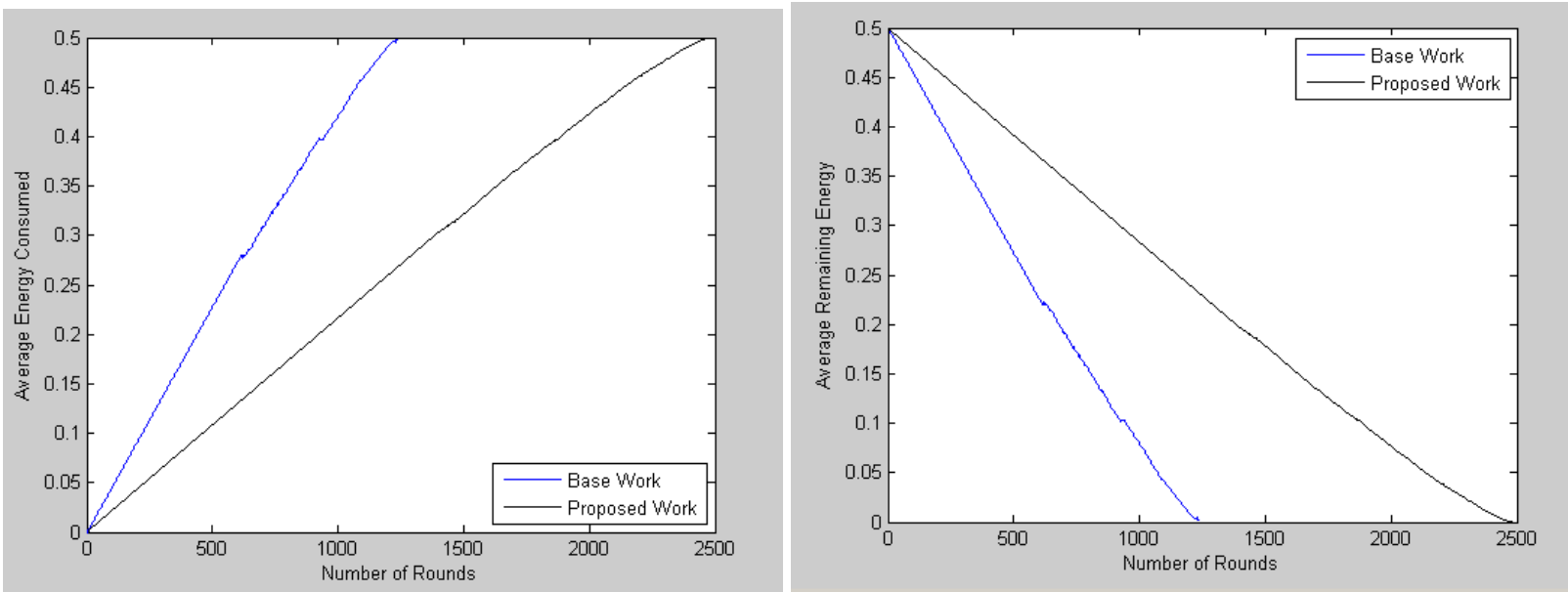

Figure 6. Energy consumed and remaining energy

\section{PACKETS SENT TO CLUSTER HEAD}

The number of packets sent to the cluster head by the sensor nodes are available inside the figure 7 . This figure illustrates the packets sent to the cluster head in the existing work and the present work. The present work is sending more number of packets to cluster head in comparison with the existing work as the network lifetime of the present work is comparatively more than the network lifetime of the existing work. The packets sent to the cluster head are shown for different number of rounds.

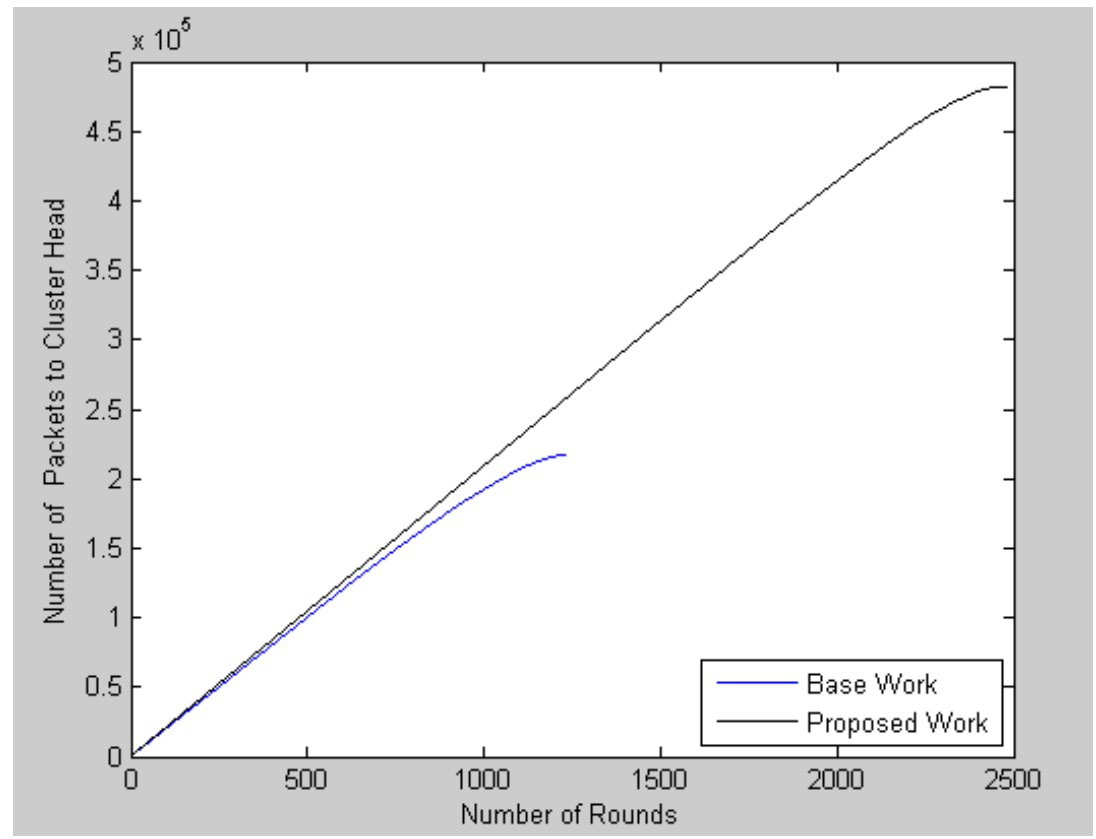

Figure 7. Packets sent to cluster head

\section{CONCLUSION AND FUTURE SCOPE}

The lower cost and easier installation of the WSNs than the wired counterpart pushes industry and academia to pay more attention to this promising technology. Large scale networks of small energy-constrained sensor nodes require techniques and protocols which are scalable, robust, and energy-efficient. We modified the region based clustering by dividing the network area into $n$ regions with cluster head chosen for each region and proposed a new method for cluster head selection having less computational complexity. The performance may be increased by considering energy as a parameter during clustering itself. Multiple number of experiments have been conducted to evaluate the effectiveness of the experiments. Due to the potential deployment in uncontrolled and harsh environments and due to the complex architecture, wireless sensor networks are and will be prone to a variety of malfunctioning. In future work, the detection accuracy for the nodes in the Wireless Sensor Network can be calculated where detection accuracy depicts the ratio of the number of faulty sensors detected to the total number of faulty sensors in the network. In the present work, we have improved the overall lifetime of the network but the faults occur inside the WSN can be analyzed in the future in real time scenarios. 


\section{REFERENCES}

[1] Abbasi, A. A., \& Mohamad, Y. [2007], "A survey on clustering algorithms for wireless sensor networks. Computer Communications", 30, 2826-2841.

[2] Akkaya, K., \& Younis, M. [2005], "A survey on routing protocols for wireless sensor networks. Ad Hoc Networks", 3 , 325-349.

[3] Acharya, S., and Tripathy, C. R. [2015], "An ANN Approach for Fault Tolerant Wireless Sensor Networks", in Emerging ICT for Bridging the Future-Proceedings of the 49th Annual Convention of the Computer Society of India CSI Volume 2 (pp. 475-483). Springer International Publishing.

[4] Prakash, T. S., Raja, K. B., Venugopal, K. R., lyengar, S. S., and Patnaik, L. M. [2014], "Fault Tolerant QoS Adaptive Clustering for Wireless Sensor Networks. In Proceedings of Ninth International Conference on Wireless Communication and Sensor Networks", (pp. 167-175). Springer India.

[5] Nesrine, K., and Ben Jemaa, M. [2012], "HEERP Hierarchical energy efficient routing protocol for Wireless Sensor Networks", in Communications and Information Technology (ICCIT), 2012 International Conference on (pp. 308-313). IEEE.

[6] Yu, J., Qi, Y., Wang, G., and Gu, X. [2012], "A cluster-based routing protocol for wireless sensor networks with non uniform node distribution", AEU-International Journal of Electronics and Communications, 66(1), 54-61.

[7] Kumar, N., Bhutani, P., and Mishra, P. [2012], "U-LEACH: A novel routing protocol for heterogeneous Wireless Sensor Networks", in Communication, Information \& Computing Technology (ICCICT), 2012 International Conference on (pp. 1-4). IEEE.

[8] Patle, D., and Nemade, S. [2015], "A Literature Survey on Different Type of Energy Efficiently Routing Protocol in Wireless Sensor Network. International Journal of Scientific Engineering and Technology", 4(1), 28-31.

[9] Ravi, M., and Subramaniam, P. [2014], "Wireless Sensor Network and its Security-A Survey", International Journal of Science and Research (IJSR), 3(12)

[10] Sun, F., Zhao, Z., Fang, Z., Du, L., Xu, Z., \& Chen, D. [2014], "A Review of Attacks and Security Protocols for Wireless Sensor Networks", Journal of Networks, 9(5), 1103-1113.

[11] S.Sudha, N. Hemavathi [2014], "A Hybrid Clustering Algorithm for Optimal Clustering in Wireless Sensor Networks". IEEE 2014.

[12] Kamanashis Biswas,Vallipuram Muthukkumarasamy,Elankayer Sithirasenan [2013], "Maximal Clique Based Clustering Scheme for Wireless Sensor Networks", 978-1-4673-5501-8/13/2013 IEEE

[13] Raza H. Abedi, Nauman Aslam and Sayeed Ghani [2011], "Fault Tolerance Analysis of Heterogeneous Wireless Sensor Network", 978-0-7695-4466-8/11/2011 IEEE.

[14] Lutful Karim and Nidal Nasser [2011], "Energy Efficient and Fault Tolerant Routing Protocol for Mobile Sensor Network", 978-1-61284-233-2/11/2011 IEEE.

[15] Geetha D.,Nalini N. and R. C. Biradar [2012], "Active Node based Fault Tolerance in Wireless Sensor Network", 978 1-4673-2272-0/12/2012 IEEE.

[16] Mohamed Lehsaini and Chifaa Tabet Hellel [2012], "A Novel Cluster-based Fault-tolerant Scheme for Wireless Sensor Networks",2012 24th International Conference on Microelectronics (ICM).

[17] Arunanshu Mahapatro and Pabitra Mohan Khilar. [2013], "Fault Diagnosis in Wireless Sensor Networks: A Survey", IEEE Communications Surveys \& Tutorials ,Vol.15, No 4.

[18] K. Kulothungan, J. Angel Arul Jothi, A. Kannan [2011], "An Adaptive Fault Tolerant Routing Protocol with Error Reporting Scheme for Wireless Sensor Networks", European Journal of Scientific Research, Vol. 16, pp, 19-32, No.1, 2011.

[19] K Abbas Nayebi, Hamid Sarbazi-Azad [2011], "Performance modeling of the LEACH protocol for mobile wireless sensor networks”, J. Parallel Distrib. Comput. 71, ELSEVIER pp. 812-821, 2011.

[20] Vinay Kumar, Sanjeev Jain and Sudarshan Tiwari [2011], "Energy Efficient Clustering Algorithms in Wireless Sensor Networks", IJCSI, Vol. 8 , 2011. 